Johan Leman, Stef Janssens

\section{Human Trafficking and Migrant Smuggling in Southeast Europe and Russia: Learning Criminal Entrepreneurship and Traditional Culture}

London - New York: Palgrave Macmillan, 2015, 172 str.

DOI: $10.11567 / m e t .31 .3 .6$

Knjiga Human Trafficking and Migrant Smuggling in Southeast Europe and Russia, podnaslova Learning Criminal Entrepreneurship and Traditional Culture, bavi se temom trgovanja ljudima i krijumčarenja migranata iz zemalja jugoistočne Europe i Rusije i preko njih u Belgiju. Zemlje jugoistočne Europe na koje se autori referiraju u svojoj studiji uključuju Albaniju, Bugarsku i Rumunjsku, dok se sintagma "preko jugoistočne Europe« odnosi na mreže trgovanja ljudima i krijumčarenja migranata koje potječu iz Turske, Iraka, Indije, Pakistana i Kine, u slučajevima kada postoji suradnja s jednom ili više mreža iz jugoistočne Europe i Rusije ili kada lanci trgovanja i krijumčarenja putuju preko neke istočnoeuropske zemlje.

Knjiga je rezultat dugogodišnjeg rada autorâ na području borbe protiv trgovanja ljudima i krijumčarenja migranata. Johan Leman, trenutačno professor emeritus socijalne i kulturne antropologije na Katoličkom sveučilištu u Leuvenu, bio je deset godina direktor Centra za jednakost mogućnosti i opoziciju rasizmu (Centre for Equal Opportunities and Opposition to Racism), što je de facto belgijski nacionalni izvjestitelj o borbi protiv trgovanja ljudima i krijumčarenja migranata. Stef Janssens analitičar je i stručnjak iz područja trgovanja ljudi- ma i krijumčarenja migranata koji radi s Europskom komisijom i sudjeluje na sastancima nacionalnih izvjestitelja o trgovanju ljudima.

Za definiranje osnovnih pojmova autori su se služili Protokolom Ujedinjenih naroda, prema kojemu krijumčarenje migranata znači "posredovanje u svrhu izravnog ili neizravnog stjecanja financijske ili druge materijalne koristi i nezakonitog ulaska osobe u državu koje ta osoba nije državljanin ili u njoj nema trajno boravište «, dok je o trgovanju ljudi riječ onda kada postoji »izrabljivanje, uključujući seksualno iskorištavanje, prisilni rad ili usluge, ropstvo ili odnose slične ropstvu, podčinjavanje ili odstranjivanje organa« (str. 6).

Knjiga se temelji na istraživanjima 134 belgijska sudska dosjea od 1994. do 2015., od kojih se devedeset odnosi na trgovanje ljudima bez elemenata krijumčarenja migranata (u 63 slučaja riječ je o trgovanju u svrhu seksualnog iskorištavanja, a u 27 o trgovanju u svrhu iskorištavanja radne snage), 34 na krijumčarenje migranata, a deset su kombinacija trgovanja ljudima i krijumčarenja migranata. Analizirani sudski dosjei obuhvatili su albanske, rumunjsko-romske, bugarske, ruske te indijsko-pakistanske kriminalne mreže, s napomenom da referiranje na etničko ili nacionalno porijeklo mreže nikako ne sugerira da se ono može shvatiti kao karakteristično za određenu etničku skupinu.

Knjiga je podijeljena na šest dijelova. Prvi dio »Networks: Rational and Cultural Components«, ujedno i uvod u knjigu, predstavlja empirijske i konceptualne pristupe autorâ. Pri istraživanju sudskih dosjea autore su prije svega zanimale racionalnost i pozicija tradicionalne kulture unutar krimi- 
nalnog biznisa. Racionalna perspektiva povezana je s konceptom »kalkuliranog poduzetništva«: kriminalci koji se bave trgovanjem ljudima i krijumčarenjem migranata $\mathrm{u}$ biti su poslovni ljudi koje zanimaju moderno upravljanje, specijalizacija, podugovaranje, fleksibilni savezi i infrastrukture, a sve radi maksimiziranja profita. Njihovo poslovanje obuhvaća različite razine; na primjer značajnu ulogu u njemu imaju putnički agenti i prijevozničke tvrtke, a jednako tako i »sigurne kuće«, mjesta u kojima se žrtve trgovanja ljudima i krijumčarenja migranata privremeno smještaju, kontroliraju i po potrebi discipliniraju. Koncepti društvenih mreža i društvenoga kapitala također se objašnjavaju u prvom poglavlju. Društveno umrežavanje često je kompromis između racionalnosti i tradicionalne kulture - njenih praksi i vrijednosti. Tamo gdje poslovni odnosi nisu legalni međusobno povjerenje postaje racionalno utemeljeno, a službene sustave nadzora zamjenjuju kontrolni mehanizmi društvenih odnosa. Sljedeći važni koncept koji Leman i Janssens uvode i u cijeloj ga studiji upotrebljavaju jest »učeća organizacija " (learning organization, str. 17), pri čemu autori naglašavaju da su analizirane kriminalne mreže organizacije koje uče i pritom su gotovo uvijek u mogućnosti preduhitriti korake vlasti, a što je još jedan jasni indikator racionalnosti koja biznis održava živim.

U drugom dijelu »Leadership and Structures « autori analiziraju načine funkcioniranja kriminalnog poduzetništva, tj. vrste rukovodećih i osnivačkih struktura koje su pronašli unutar velikih kriminalnih mreža iz sudskih dosjea. Detaljno opisuju pet kategorija poduzetničkih struktura i načina vo- đenja biznisa: mreže klanova koje se ne koriste strukturom tvrtke, poslovne mreže, međunarodne i međuetničke mreže, uključenost mafije i/ili (bivših) državnih sigurnosnih službi te mreže nalik na mafiju. Pojedini slučajevi obuhvaćaju i više od jednog načina poslovanja, a u svim su slučajevima autori pronašli dva dominantna principa koja određuju način osnivanja i vođenja kriminalnog biznisa: jedan su klanski ili obiteljski odnosi, a drugi poslovne mreže zasnovane na prethodnoj poslovnoj suradnji na drugim područjima, uglavnom s poveznicom na sigurnosne službe (na primjer one iz bivših socijalističkih režima u Albaniji, Bugarskoj i Rusiji). Isto tako, tradicionalna kultura vrlo je prisutna u svim razmatranim slučajevima, a posebno su analizirani slučajevi kada se dijelovi albanske kulture $\mathrm{Ka}$ nun i romske Kumpania upotrebljavaju (i po potrebi modificiraju) u kriminalnom poslovanju.

U trećem dijelu »Making the $\mathrm{Bu}$ siness Operational« Leman i Janssens analiziraju metodologiju kojom se služe kriminalni poduzetnici kako bi razvili biznis. Strukture korisne u poslovanju vezanom uz trgovanje ljudima i krijumčarenja migranata jesu prijevozničke tvrtke, putničke agencije, mješavina agencija za zapošljavanje i putničkih agencija te sigurne kuće. Autori opisuju i dodatne aktivnosti vezane uz trgovanje ljudima i krijumčarenje migranata pronađene $u$ analiziranim dosjeima: falsificiranje dokumenata, korupciju nekih službenika u zemljama porijekla žrtava trgovanja ljudima i krijumčarenja migranata i korupciju nekih službenika u veleposlanstvima zapadnih zemalja. Obrađuju i područja tradicionalne kulture (primjerice tehniku loverboys koja se odno- 
si na ljubavnike koji služe za regrutiranje žrtava, ili nasilno manipuliranje tradicionalnom kulturom), mehanizam kontrole kroz zaduživanje žrtava, tehnike stvaranja ovisnosti žrtava o drogama te fizičko nasilje kriminalaca nad žrtvama.

Četvrti dio »Increasing Benefits, Decreasing Risks; The Impact of Learning « objašnjava na koje se načine kriminalci bore s jedne strane protiv konkurenata, a s druge protiv vlade koja želi uništiti njihov biznis. Analizirani sudski slučajevi pokazuju da kriminalci diversificiraju poslovanje tako što se uključuju i u druge ilegalne prakse (prodaja droge i organizacija ljudi koji za njih prose) i terorizam. Posljednjih godina dosta se njih koristi i posrednicima, na primjer »velikim sestrama« pratiljama, koje istovremeno nadziru žrtve seksualnog iskorištavanja i posrednice su između žrtve i svodnika. Većina je analiziranih slučajeva pokazala da u poslu opstaju samo oni kriminalci koji su spremni na proaktivno učenje i koji su uvijek korak ispred policije.

Peti dio knjige »Money, Money, Money...Always Sunny! « istražuje financijske aspekte trgovanja ljudima i krijumčarenja migranata: profite, tokove novčanih transakcija, pranje novca, ulaganja i dr. Podaci iz sudskih dosjea pokazuju da veliki novčani iznosi ostaju u cirkulaciji nakon pranja novca i izvan su dosega državnih tijela. Pokazalo se da se neki kulturom definirani sustavi novčanih transakcija (kao što je Hawala) uspješno upotrebljavaju za službeno neregistrirane transfere novca unutar europskih zemalja i izvan njih.

U zadnjem dijelu knjige »Rational and Cultural: Conclusions and Poli- cy Proposals « autori iznose zaključke i preporuke za djelovanje na razini nacionalnih i europskih politika. Izdvojit ćemo samo neke: za učinkovitiju borbu protiv krijumčarenja migranata potrebna je bolje smišljena, pozitivna i transparentna globalna europska migracijska politika; financijske istrage ključne su za otkrivanje i osuđivanje kriminalnih organizacija i na tom je području nužna bolja međunarodna suradnja; potrebno je poboljšati radne uvjete i sustave socijalne zaštite $\mathrm{u}$ državama iz kojih dolaze migranti; u državama u koje dolaze migranti potrebno je provoditi bolji nadzor sustava socijalne zaštite, uključujući kontrolu rada na crno.

Prema riječima Louise Shelley, koja je napisala predgovor, ova je knjiga prva studija koja je detaljno ispitala i analizirala sudske slučajeve trgovanja ljudima i krijumčarenja migranata u jednoj europskoj zemlji. Možemo tome dodati i da je knjiga značajna jer osvjetljava razvoj događanja oko kriminalnih skupina iz jugoistočne Europe i Rusije u posljednjih dvadeset godina te opisuje i objašnjava ulogu tradicionalne kulture u njihovu poslovanju. Pisana je vrlo jednostavnim i tečnim jezikom, a posebno su zanimljivi konkretni sudski slučajevi, koji su detaljno opisani i na kojima se temelje analize i zaključci autorâ. Zaključno može se reći da je knjiga Lemana i Janssensa odlično štivo za sociologe, antropologe, kriminaliste, ali i sve druge stručnjake i čitatelje koje zanima tematika trgovanja ljudima i krijumčarenja migranata.

Rahela Jurković

Zagreb 